\title{
Influence of acetylator phenotype on the haematological and biochemical effects associated with dapsone in leprosy patients
}

\author{
R.H.C. QUEIROZ*, A.M. SOUZA, E. MELCHIOR, \\ E.G. GOUVEIA \& D. CARVALHO \\ Department of Clinical, Toxicological and Food Sciences Analysis, \\ Faculty of Pharmaceutical Sciences of São Paulo, Av. do Café s/n- \\ 14040-903 - Ribeirão Preto, S.P., Brazil
}

Accepted for publication 7 May 1997

\begin{abstract}
Summary Methaemoglobinaemia and haemolytic anaemia were the principal side-effects observed in 30 leprosy patients undergoing long-term treatment with dapsone as a single drug or as part of multidrug therapy. Hepatic, pancreatic and renal evaluations showed no relevant clinical changes. Since N-acetylation is a major metabolic pathway for dapsone, slow acetylation phenotype may be a risk factor for the development of these reactions. To confirm this hypothesis we correlated acetylator phenotype and the haematological and biochemical effects induced by dapsone.

No excess proportion of slow acetylators was found. We conclude that slow acetylators are not at greater risk of developing haematological side-effects of dapsone than fast acetylators.
\end{abstract}

\section{Introduction}

$\mathrm{N}$-acetyltransferases play an important role in the biotransformation of a number of clinically useful drugs such as isoniazid, procainamide, hydralazine, dapsone, sulphamethazine as well as some carcinogenic arylamines ${ }^{1}$. In some cases, acetylation capacity has been shown to be related to variation in drug response, susceptibility to adverse reactions and increased incidence of certain spontaneous disorders including cancer. ${ }^{2-6}$

Dapsone is a widely used drug, extensively employed in the treatment of leprosy ${ }^{7}$ and the prophylaxis of malaria, ${ }^{8}$ and more recently in the treatment of Pneumocystis carinii pneumonia in AIDS patients. ${ }^{9}$ A number of side-effects are associated with dapsone therapy, including methaemoglobinaemia and oxidative haemolysis, haematological effects that frequently limit its clinical use. ${ }^{10,11}$

Zuidema et al. ${ }^{12}$ reported no difference in serum or plasma concentration or in any pharmacokinetic parameters of dapsone or monoacetyldapsone between slow and fast acetylators. Also, the therapeutic response was the same for both acetylator phenotypes. 
It has been speculated that slow acetylators may have relatively more of the parent drug available for oxidative metabolism by cytochrome P-450 and thus may be at an increased risk to develop haematological side-effects in response to dapsone. ${ }^{13}$ Although there is preliminary evidence that patients with the slow acetylator phenotype may be disproportionately represented among patients with haematological side effects, no conlusive data are available in the literature about the possible side effects of long-term treatment.

To confirm this preliminary finding, we investigated the influence of acetylation phenotype on the haematological and biochemical effects of a group of leprosy patients who were submitted to long-term treatment with dapsone as a single drug or as part of multidrug therapy (MDT), i.e., dapsone plus clofazimine plus rifampicin.

\section{Methods}

LEPROSY PATIENTS

Thirty white Brazilian leprosy patients (14 females and 16 males) on dapsone treatment for at least 6 months as a single drug or as part of multidrug therapy, seen at the Regional Sanitary Dermatology Outpatient Clinic of Ribeirão Preto (ARE-DSRP) participated in this study. No patient had a history of sulphonamide allergy or glucose-6phosphate dehydrogenase (G-6-PD) deficiency. Social alcohol intake was permitted, but chronic heavy alcohol users were excluded from the study. Elderly patients (older than 65 years), patients with acquired immunodeficiency and pregnant women were also excluded. The patients were divided into three groups according to therapeutic schedule: Control Group - 15 patients of both sexes who had been on MDT for at least six months previously but who had been off all medication for a period of 6 months or more at the time of the study, with clinically and bacilloscopically inactive disease. The controls did not receive any medication during the study. DDS Group - 15 patients of both sexes treated with $100 \mathrm{mg} /$ day dapsone. Group MDT -15 patients of both sexes given dapsone $100 \mathrm{mg}$ /day dapsone plus $100 \mathrm{mg}$ /day clofazimine on alternate days, and a $300 \mathrm{mg}$ dose given once a month under supervision, plus rifampicin, $600 \mathrm{mg}$ once a month under supervision.

\section{ACETYLATION PHENOTYPING}

A single $2.5 \mathrm{ml}$ heparinized blood sample was obtained $12 \mathrm{hr}$ after administration of the daily dose of dapsone (CEME, Brasília, Brazil). Plasma was separated by centrifugation and stored at -20C pending analysis. The phenotype criterion of Reidenberg et al., ${ }^{14}$ i.e., a plasma (MADDS/DDS) ratio of less than $0 \cdot 30$, indicated slow acetylators.

\section{ANALYSIS}

Plasma dapsone and monoacetyldapsone concentrations were measured by the HPLC method of Queiroz et al. (in press), as follows.

A 1-ml aliquot of plasma supplemented with the internal standard (50 $\mu \mathrm{l}$ of the phenacetin solution) was alkalinized with $200 \mu \mathrm{l}$ of a $1.5 \mathrm{~N}$ sodium hydroxide solution and extracted with $7 \mathrm{ml}$ ethyl ether for $30 \mathrm{~min}$ in a mechanical shaker after the addition of $200 \mathrm{mg}$ sodium chloride. The samples were centrifuged at $3000 \mathrm{rpm}$ for $10 \mathrm{~min}$ and the 
organic phases transferred to conic tubes to which $50 \mu 11 \mathrm{~N} \mathrm{HCl}$ in methanol were added. After extract evaporation under an air flow at room temperature the residues were reconstituted with $50 \mu \mathrm{l}$ of the mobile phase and $50 \mu \mathrm{l}$ of $\mathrm{n}$-hexane. After shaking in a mixer for $1 \mathrm{~min}$ and centrifugation, $20 \mu \mathrm{l}$ of the mobile phase were injected into the liquid chromatography apparatus.

Chromatography was performed using a Varian liquid chromatography apparatus model 5000 equipped with a Rheodyne injector model 7125 with a $20 \mu \mathrm{l}$ sampler and a Varian ultraviolet absorbance detector model UV-100 operating at $286 \mathrm{~nm}$. The chromatograms were obtained with a Varian integrator model 4290. Analysis was carried out on a reverse phase $\mathrm{C}_{8}$ LiChrocart ${ }^{\circledR} 100$ column $(4 \times 125 \mathrm{~mm}$, Merck) with $5 \mu \mathrm{m}$ particles. The mobile phase used was a water:methanol mixture $(70: 30 \mathrm{v} / \mathrm{v})$ with a flow of $1 \mathrm{ml} \mathrm{min}^{-1}$.

\section{BIOCHEMICAL AND HAEMATOLOGIC PARAMETERS}

Three blood samples were collected from each patient at weekly intervals for a more judicious evaluation of haematological and biochemical data. The results obtained (means $\pm \mathrm{SD}$ ) were compared with those obtained for the controls. The samples were obtained in the morning from fasted patients after a protocol had been filled out with patient name, age, sex, weight, scheduled medication, collection time and associated medications. The study of the adverse effects of dapsone was carried out haematologically level (blood count, reticulocytes, osmotic fragility, detection of Heinz bodies and methaemoglobinaemia) and biochemically (transaminases, bilirubins, alkaline phosphatase, gamma-glutamyltransferase, amylase, urea, creatinine, and potassium).

\section{GLUCOSE-6-PHOSPHATE DEHYDROGENASE}

Glucose-6-phosphate dehydrogenase levels were measured by the spectrophotometric method of Lohr \& Waller ${ }^{15}$ using Sigma Diagnostics ${ }^{\circledR}$ (St Louis, MO, USA) reagents which are for quantitative, ultraviolet, kinetic determination in blood at $340 \mathrm{~nm}$.

\section{STATISTICAL METHODS}

Data were analysed statistically by ANOVA and by the multiple comparisons post test (Tukey-Kramer) using the GraphPad Instant ${ }^{\circledR}$ and Statgraphics ${ }^{\circledR}$ software, with the level of significance set at $p<0 \cdot 05$.

\section{Results}

None of the 30 leprosy patients were found to have G-6-PD deficiency. The acetylation phenotype was determined on the basis of the ratio of plasma MADDS and DDS concentration. The mean values $( \pm \mathrm{SD})$ for slow (13) and fast acetylators (17) were $0 \cdot 28 \pm 0.05$ and $0.57 \pm 0 \cdot 01$, respectively. The percentages of slow and fast acetylators among the leprosy patients in the two groups studied were 43.3 and $56 \cdot 7$, respectively.

The haematologic and biochemical abnormalities observed in slow and fast acetylators are shown in Table 1 and are reported as means $\pm \mathrm{SD}$ of the data for the slow and fast acetylator groups compared with control. Haemolytic anaemia in addition to 
Table 1 Tukey-Kramer multiple comparison test of haematology and biochemical data

\begin{tabular}{|c|c|c|c|c|}
\hline \multirow[b]{2}{*}{ Parameter } & \multirow[b]{2}{*}{$\begin{array}{l}\text { Control }(n=15) \\
\quad \text { Mean } \pm \text { SD }\end{array}$} & \multicolumn{2}{|c|}{ Acetylators } & \multirow[b]{2}{*}{$\begin{array}{c}\text { Slow } \\
\text { vs Fast } \\
P \text { value }\end{array}$} \\
\hline & & $\begin{array}{c}\text { Slow }(n=13) \\
\text { mean } \pm \mathrm{SD} \\
(95 \% \mathrm{CI})\end{array}$ & $\begin{array}{c}\text { Fast }(n=17) \\
\text { mean } \pm \mathrm{SD} \\
(95 \% \mathrm{CI})\end{array}$ & \\
\hline Red cell count (million $/ \mathrm{mm}^{3}$ ) & $5 \cdot 19 \pm 0 \cdot 28$ & $\begin{array}{l}3.95 \pm 0.46 \dagger \\
(3.67-4 \cdot 22)\end{array}$ & $\begin{array}{l}4.25 \pm 0.39 \dagger \\
(4.05-4.46)\end{array}$ & NS \\
\hline $\begin{array}{l}\text { Packed cell volume }(\mathrm{PCV}) \\
(\%)\end{array}$ & $45 \cdot 80 \pm 2 \cdot 70$ & $\begin{array}{r}34 \cdot 54 \pm 4.05 \dagger \\
(32.08-36.98)\end{array}$ & $\begin{array}{c}36.94 \pm 3.68 \dagger \\
(35.04-38.83)\end{array}$ & NS \\
\hline Haemoglobin $(\mathrm{g} / \mathrm{dl})$ & $14 \cdot 78 \pm 0 \cdot 83$ & $\begin{array}{l}10 \cdot 39 \pm 1 \cdot 62 \dagger \\
(9 \cdot 41-11 \cdot 37)\end{array}$ & $\begin{array}{c}11 \cdot 17 \pm 1 \cdot 34 \dagger \\
(10 \cdot 48-11 \cdot 86)\end{array}$ & NS \\
\hline $\begin{array}{l}\text { Mean cell } \\
\text { haemoglobin }(\mathrm{MCH})(\mathrm{pg})\end{array}$ & $28 \cdot 46 \pm 0 \cdot 88$ & $\begin{array}{r}26 \cdot 17 \pm 1 \cdot 64 \dagger \\
(26 \cdot 18-27 \cdot 17)\end{array}$ & $\begin{array}{c}26 \cdot 20 \pm 1 \cdot 16 \dagger \\
(25 \cdot 60-26 \cdot 80)\end{array}$ & NS \\
\hline $\begin{array}{l}\text { Mean cell haemoglobin } \\
\text { concentration }(\mathrm{g} / \mathrm{dl})\end{array}$ & $32 \cdot 32 \pm 1 \cdot 00$ & $\begin{array}{r}29.97 \pm 1.80 \dagger \\
(28.88-31.06)\end{array}$ & $\begin{array}{c}29 \cdot 76 \pm 1.66 \dagger \\
(28.90-30 \cdot 62)\end{array}$ & NS \\
\hline $\begin{array}{l}\text { Reticulocyte } \\
\text { count }(\%)\end{array}$ & $0.90 \pm 0.08$ & $\begin{array}{l}2 \cdot 16 \pm 0.89 \dagger \\
(1 \cdot 41-2 \cdot 91)\end{array}$ & $\begin{array}{c}2 \cdot 55 \pm 1 \cdot 36 \dagger \\
(1 \cdot 28-3 \cdot 81)\end{array}$ & NS \\
\hline Methaemoglobin (\%) & $0.99 \pm 0 \cdot 34$ & $\begin{array}{l}6 \cdot 92 \pm 1 \cdot 36 \dagger \\
(6 \cdot 10-7 \cdot 74)\end{array}$ & $\begin{array}{l}5 \cdot 97 \pm 1 \cdot 56 \dagger \\
(5 \cdot 16-6 \cdot 78)\end{array}$ & NS \\
\hline Eosinophilis $\left(\mathrm{mm}^{3}\right)$ & $246 \cdot 93 \pm 180 \cdot 01$ & $\begin{array}{l}787 \cdot 86 \pm 482 \cdot 43 \dagger \\
(520 \cdot 7-1,055 \cdot 1)\end{array}$ & $\begin{array}{c}775 \cdot 6 \pm 617 \cdot 1 \dagger \\
(433 \cdot 83-1,117 \cdot 4)\end{array}$ & NS \\
\hline Lymphocytes $\left(\mathrm{mm}^{3}\right)$ & $2,285 \cdot 20 \pm 661 \cdot 28$ & $\begin{array}{l}1,595 \cdot 12 \pm 470 \cdot 94^{*} \\
(1,201 \cdot 4-1,988 \cdot 9)\end{array}$ & $\begin{array}{l}1,834 \cdot 28 \pm 319 \cdot 07^{*} \\
(1,539 \cdot 2-2,129 \cdot 4)\end{array}$ & NS \\
\hline Total billirubin $(\mathrm{mg} / \mathrm{dl})$ & $0 \cdot 74 \pm 0 \cdot 12$ & $\begin{array}{l}0 \cdot 83 \pm 0 \cdot 13^{*} \\
(0 \cdot 75-0 \cdot 91)\end{array}$ & $\begin{array}{l}0.92 \pm 0 \cdot 22 * \\
(0 \cdot 79-1.04)\end{array}$ & NS \\
\hline Creatinine (mg/dl) & $0.94 \pm 0.08$ & $\begin{array}{l}1 \cdot 19 \pm 0 \cdot 12 * \\
(1 \cdot 04-1 \cdot 19)\end{array}$ & $\begin{array}{l}1 \cdot 24 \pm 0 \cdot 15^{*} \\
(1 \cdot 16-1 \cdot 32)\end{array}$ & NS \\
\hline Potassium (mEq/L) & $3.94 \pm 0.33$ & $\begin{array}{l}4 \cdot 09 \pm 0 \cdot 23^{*} \\
(3 \cdot 95-4 \cdot 23)\end{array}$ & $\begin{array}{l}4 \cdot 22 \pm 0 \cdot 33^{*} \\
(4 \cdot 05-4 \cdot 40)\end{array}$ & NS \\
\hline
\end{tabular}

* Analysis of variance $-P<0.05$.

$\dagger$ Analysis of variance $-P<0.01$.

NS - not significant $(P>0.05)$.

methaemoglobinaemia was also detected in fast and slow acetylators. Thirteen patients (6 slow and 7 fast acetylators) had anaemia with haemoglobin levels of $7 \cdot 2-10 \cdot 9 \mathrm{~g} / \mathrm{dL}$ and packed cell volumes of $28 \%-37 \%$. Reduction in total red cell number, macrocytosis, poikilocytosis and hypochromia were detected in most patients. Eleven males (5 slow and 6 fast acetylators) had normocytic, normochromic anaemia (haemoglobin levels of $10 \cdot 9-12 \cdot 3 \mathrm{~g} / \mathrm{dL}$ and packed cell volumes of $33 \%-37 \%)$. The other patients had anisocytosis or poikilocytosis. Reticulocyte counts were elevated ( $>1.8 \%$ ) in $80 \%$ of the patients. The haemolytic action of dapsone was also evaluated by the osmotic fragility test, and a reduction in cell resistance was detected in $100 \%$ of the patients compared to controls regardless of acetylator phenotype. Heinz bodies were only detected in slow acetylators $(6 \%)$.

Differential white cell counts showed significant eosinophilia for both slow $(46 \cdot 6 \%)$ and fast $(53.3 \%)$ acetylators. Since no clinical symptoms or parasite infection that might cause the eosinophilia were detected, we postulated this as a possible allergic reaction to the medication.

Hepatic, pancreatic and renal evaluation by biochemical parameters showed occasional changes of no apparent clinical significance, although creatinine, potassium and 
bilirubin values showed statistically significantly differences compared to the control when the data were submitted to analysis of variance (ANOVA), Table I.

The influence of acetylator phenotype on the haematologic and biochemical effects associated with long-term dapsone treatment was evaluated by the Tukey-Kramer multiple comparison post test (Table I). Comparison of the haematological and biochemical parameters of the patients classified as slow and fast acetylators did not reveal statistically significant differences between the two groups.

\section{Discussion}

This study did not reveal a statiscally significant excess of haematological side effects in slow acetylators among leprosy patients on long-term treatment with dapsone.

As also reported by Kelly \& Griffiths, ${ }^{16}$ we failed to observe any association between acetylator status and severity of haemolysis or methaemoglobinaemia, side-effects, which are thought to be mediated by the hydroxylamine metabolites. ${ }^{17}$

Dapsone hydroxylamine reacts with oxyhaemoglobin $\left(\mathrm{Fe}^{2+}\right)$ to form methaemoglobin $\left(\mathrm{Fe}^{3+}\right)$ and the nitrosoarene, which is in turn reduced to the hydroxylamine by either NADPH methaemoglobin reductases or glutathione. Each hydroxylamine molecule is capable of oxidizing up to five oxyhaemoglobin molecules, and the cycle only ceases when the erythrocyte is almost totally depleted of glutathione. As methaemoglobin cannot carry oxygen, it may cause, in proportion to blood levels, lethargy, headache, cyanosis, dyspnoea, tachycardia, nausea and, in extreme cases, death. Methaemoglobin levels of under $20 \%$ are not usually associated with symptoms, although in our study four females, with $8 \cdot 1-9 \cdot 8 \%$ methaemoglobinaemia reported symptoms of lethargy, headache and nausea. This is consistent with literature showing that some patients cannot tolerate even low levels of methaemoglobinaemia. ${ }^{10,11}$

Dapsone therapy also reduces erythrocyte survival time. Recent studies on rats have suggested that the hydroxylamine promotes the formation of disulphide-linked adducts between haemoglobin and red cell skeletal proteins. Dapsone hydroxylamine also interferes with potassium and chloride cotransport within rat red cells, and causes them to shrink and become less deformable. Overall, after exposure to dapsone hydroxylamine, erythrocytes are recognized as aged and prematurely removed from the circulation by the spleen. The presence of Heinz bodies has also been associated with reactive biotransformation products resulting from the oxidative denaturation of haemoglobin. ${ }^{10,11}$

Studies reporting the occurence of haemolysis and anaemia induced by dapsone have suggested that these clinical symptoms occur mainly in the presence of high doses ( $>100 \mathrm{mg} /$ day) of the medication or in G-6-PD deficient patients. ${ }^{17}$ However, in our study we showed that in patients with normal G-6-PD levels on therapeutic doses of $100 \mathrm{mg} /$ day dapsone, some of them developed anaemia (44\%) (Table I). And as also reported by Byrd \& Gelber, ${ }^{18}$ we observed that chronic dapsone treatment results in not only haemolysis but a significant decrease in haemoglobin concentration.

Attempts have been made to counteract the haemotoxic effects of the metabolite by the use of antioxidants such as vitamins $\mathrm{E}$ and $\mathrm{C} .{ }^{10}$ Recently, the coadministration of a metabolic inhibitor such as cimetidine has been shown to reduce significantly dapsonedependent methaemoglobinaemia, without any change in drug efficacy . Such a therapeutic 
strategy may be appropriate for patients who require high-dose dapsone and for those who are particularly susceptible to dapsone-induced haemotoxicity. ${ }^{19}$

This study, therefore, while supporting the view that a long-term treatment of dapsone $(100 \mathrm{mg} /$ day $)$ may cause significant methaemoglobinaemia and haemolysis, also reveals that patients who are slow acetylators are not at greater risk of developing haematological side-effects of dapsone than fast acetylators.

\section{References}

${ }^{1}$ Evans, DAP. Acetylation. In Ethnic differences in reactions to drugs and xenobiotics, eds Kalow, W., Goedde, H.W. \& Agarwal, D.P., New York: Alan R. Liss, Inc., 1986: pp. 209-242.

2 Ilett, KF, Chiswell, GM, Spargo, RM, Platt, E, Michin, RF. Acetylation phenotype and genotype in aboriginal leprosy patients from the north-west region of Western Australia. Pharmacogenetics, 1993; 3:264269.

${ }^{3}$ Hayes, RB, Bi, W, Rothman, N, Bioly, F, Caporaso, N, Feng, P, Yow, X, Yim, S, Woosley, RL, Meyer, UA. N-acetylation phenotype and genotype and risk of bladder cancer in benzidine-exposed workers. Carcinogenesis, 1993; 14:675-678.

4 Reidenberg, MM, Drayer, DE, Lorenzo, B, Strom, BL, West, SL, Snyder, ES, Freundlich, B, Stolley, PD. Acetylation phenotypes and environmental chemical exposure of people with idiopathic systemic lupus erythematosus. Arthritis Rheum, 1993; 36:971-973.

5 Ong, ML, Mant, TG, Veerapen, K, Fitzgerald, D, Wang, F, Manivasagar, M, Bosco, JJ. The lack of relationship between acetylator phenotype and idiopathic systemic lupus erythematosus in a South-east Asian population: a study of Indians, Malays and Malaysian Chinese. Br J Rheumatol, 1990; 26:462-464.

6 Rothman, N, Hayes, RB, Bi, W, Caporaso, N, Broly, F, Woosley, RL, Yin, S, Feng, P, You, X, Meyer, UA. Correlation between $\mathrm{N}$-acetyltransferase activity and $\mathrm{NAT}_{2}$ genotype in chinese males. Pharmacogenetics, 1993; 3:250-255.

7 Vandher, A, Lall jee, M. Patient treatment compliance in leprosy - A critical review. Int J Lepr, 1992; 60:587607.

8 Bruce-Chwatt, LJ. Essential malariology. Heinemann, London, 1982: pp. 181-182.

9 Gallant, JE, Moore, RD, Chaisson, RE. Prophylaxis for opportunistic infections in patients with HIV infections. Ann Intern Med, 1994; 120:932-944.

10 Coleman, MD. Dapsone: modes of action toxicity and possible strategies for increasing patient tolerance. Brit J Dermatol, 1993; 129:507-513.

11 Coleman, MD. Dapsone toxicity: some current perspectives. Gen Pharmac, 1995; 26:1461-1467.

12 Zuidema, J, Hilbers-Modderman, ESM, Merkus, FWHM. Clinical pharmacokinetics of dapsone. Clin Pharmacok, 1986; 11:299-315.

13 Rieder, MJ, Shear, NH, Kanee, A, Tang, BK, Spielberg, SP. Prominence of slow acetylator phenotype among patients with sulfonamide hypersensitivity reactions. Clin Pharmacol Ther, 1991; 49:13-17.

14 Reidenberg, MM, Drayer, D, De Marco, AL, Bello, CT. Hydralazine elimination in man. Clin Pharmac Ther, 1973; 17:722-730.

15 Lohr, GW, Waller, HD. Glucose-6-phosphate dehydrogenase. In Methods of enzymatic analysis. HU Bergmeyer, Editor, Academic Press, New York, 1974: pp. 636.

16 Kelly, C, Griffiths, ID. Dapsone in rheumatoid arthritis. Ann Rheum Dis, 1981; 40:630.

17 Gill, HJ, Tingle, MD, Park, BK. N-hydroxylation of dapsone by dapsone enzymes of cytochrome P450: implications for inhibition of haematoxicity. Br J Clin Pharmacol, 1995; 40:531-538.

18 Byrd, SR, Gilber, RH. Effect of dapsone on haemoglobin concentration in patients with leprosy. Lepr Rev, - 1991; 62:171-178.

19 Rhodes, LE, Tingle, MD, Park, BK, Chu, P, Verbov, JL, Friedmann, PS. Cimetidine improves the therapeutic/toxic ratio of dapsone in patients on chronic dapsone therapy. Brit J Dermatol, 1995; 132:257-262. 